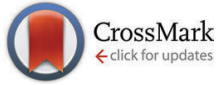

Cite this: Phys. Chem. Chem. Phys., 2015, 17, 19582

Received 1st June 2015 Accepted 1st July 2015

DOI: $10.1039 / c 5 c p 03157 e$

www.rsc.org/pccp

\title{
The low frequency modes of solvated ions and ion pairs in aqueous electrolyte solutions: iron(II) and iron(III) chloride
}

\author{
Fabian Böhm, ${ }^{a}$ Vinay Sharma, ${ }^{\mathrm{b}}$ Gerhard Schwaab*a and Martina Havenith ${ }^{a}$
}

\begin{abstract}
We have investigated the hydration dynamics of solvated iron(II) and iron(III) chloride. For this, THz/FIR absorption spectra of acidified aqueous $\mathrm{FeCl}_{2}$ and $\mathrm{FeCl}_{3}$ solutions have been measured in a frequency range of $30-350 \mathrm{~cm}^{-1}(\approx 1-10 \mathrm{THz})$. We observe a nonlinear concentration dependence of the absorption, which is attributed to the progressive formation of chloro-complexes of Fe(॥) and Fe(II), respectively. By principal component analysis of the concentration dependent absorption spectra, we deduced the molar extinction spectra of the solvated species $\mathrm{Fe}^{2+}+2 \mathrm{Cl}^{-}$and $\mathrm{FeCl}^{+}+\mathrm{Cl}^{-}$, as well as $\mathrm{FeCl}^{2+}+2 \mathrm{Cl}^{-}$ and $\mathrm{FeCl}_{2}{ }^{+}+\mathrm{Cl}^{-}$. In addition, we obtain ion association constants $\log K_{\mathrm{FeCl}_{2}}=-0.88(5)$ and $\log K_{\mathrm{FeCl}_{3}}=$ -0.32(16) for the association of $\mathrm{Fe}^{2+}$ and $\mathrm{Cl}^{-}$to $\mathrm{FeCl}^{+}$and the association of $\mathrm{FeCl}^{2+}$ and $\mathrm{Cl}^{-}$to $\mathrm{FeCl}_{2}{ }^{+}$, respectively. We performed a simultaneous fit of all the effective extinction spectra and their differences, including our previous results of solvated manganese(॥) and nickel(॥) chlorides and bromides. Thereby we were able to assign absorption peaks to vibrational modes of ion-water complexes. Furthermore, we were able to estimate a minimum number of affected water molecules, ranging from ca. 7 in the case of $\mathrm{FeCl}^{+}+\mathrm{Cl}^{-}$to $\mathrm{ca} .21$ in the case of $\mathrm{FeCl}^{2+}+\mathrm{Cl}^{-}$.
\end{abstract}

\section{Introduction}

Ion hydration phenomena have attracted the attention of many researchers. ${ }^{1-4}$ Whereas macroscopically ion hydration is well understood, at the molecular level it is still part of an ongoing and sometimes controversial discussion. ${ }^{3-8}$ Recently, the solvation dynamics of alkali and alkaline earth metals have been studied in detail. ${ }^{2,3,6-9}$ Most of these studies indicate prevalently self confined cations and anions in aqueous phase at low and moderate concentrations. ${ }^{2,6-8,10}$ In certain cases, however, cooperative effects between the ions have been postulated. ${ }^{9}$

The hydration properties of transition metal ions have only recently been studied. ${ }^{11-13}$ The behaviour of ferrous $\left(\mathrm{Fe}^{2+}\right)$ and ferric $\left(\mathrm{Fe}^{3+}\right)$ iron in aqueous solution with respect to their tendency towards formation of distinct chloro-complexes are of special interest to the fields of iron metabolism and biological function, ${ }^{14,15}$ geochemical and hydrothermal studies, ${ }^{16,17}$ isotopic fractionation ${ }^{18}$ and chemistry of natural waters. ${ }^{19}$ In spite of a broad range of technical applications, simultaneous quantitative analysis of aqueous iron(II) and iron(III) at high concentrations still remains a challenge. Calorimetry, ${ }^{20}$ isotachophoresis, ${ }^{21}$ ion chromatography ${ }^{19,22}$ and spectrophotometry ${ }^{17,23-27}$ are restricted

\footnotetext{
${ }^{a}$ Department of Physical Chemistry II, Ruhr-Universität Bochum, Germany. E-mail: gerhard.schwaab@rub.de; Fax: +49 234321 4183; Tel: +49 2343224256

${ }^{b}$ Institute of Chemistry, The Hebrew University, Jerusalem, Israel
}

to the millimolar concentration range, since the formation of ion associates complicates data evaluation at higher concentrations.

While the masses of $\mathrm{Fe}^{2+}$ and $\mathrm{Fe}^{3+}$ are practically the same, the ionic radii of the ions differ considerably $\left(0.92 \AA\right.$ for $\mathrm{Fe}^{2+}$ and $0.79 \AA$ for $\mathrm{Fe}^{3+}$ ) due to the different charge states. $\mathrm{Fe}^{3+}$ has a much higher charge density, which causes substantially different hydration behavior compared to $\mathrm{Fe}^{2+}$. Besides the octahedral hexaaqua complex $\left[\mathrm{Fe}\left(\mathrm{H}_{2} \mathrm{O}\right)_{6}\right]^{2+}$, several chloro-complex species have been identified in acidic solutions of ferrous chloride, which are: octahedral monochloro-complex $\left[\mathrm{Fe}\left(\mathrm{H}_{2} \mathrm{O}\right)_{5} \mathrm{Cl}\right]^{+}$, dichloro-complex $\left[\mathrm{Fe}\left(\mathrm{H}_{2} \mathrm{O}\right)_{4} \mathrm{Cl}_{2}\right]$, and tetrahedral tetrachlorocomplex $\left[\mathrm{FeCl}_{4}\right]^{2-} .^{28}$ The latter species, however, is formed exclusively at very high chloride excess ${ }^{29}$ and/or high temperatures. ${ }^{28,30}$ Similarly, the complexes formed by ferric chloride are: octahedral hexaaqua complex $\left[\mathrm{Fe}\left(\mathrm{H}_{2} \mathrm{O}\right)_{6}\right]^{3+}$, monochlorocomplex $\left[\mathrm{Fe}\left(\mathrm{H}_{2} \mathrm{O}\right)_{5} \mathrm{Cl}\right]^{2+}$, dichloro-complex trans- $\left[\mathrm{Fe}\left(\mathrm{H}_{2} \mathrm{O}\right)_{4} \mathrm{Cl}_{2}\right]^{+}$, trichloro-complex $\left[\mathrm{Fe}\left(\mathrm{H}_{2} \mathrm{O}\right)_{3} \mathrm{Cl}_{3}\right]$ and tetrahedral tetrachlorocomplex $\left[\mathrm{FeCl}_{4}\right]^{-17,31-41}$ Similarly to the ferrous salt, the highest order chloro-species is only found at high chloride excess and/or high temperatures.

So far, the equilibrium formation constant of the ferrous monochloro-complex at room temperature has been determined by spectrophotometry $^{28,42}$ and potentiometry ${ }^{43}$ to be $0.69 \mathrm{~kg} \mathrm{~mol}^{-1}$, $0.43 \mathrm{~kg} \mathrm{~mol}{ }^{-1}$ and $0.75 \mathrm{~kg} \mathrm{~mol}{ }^{-1}$, respectively. The formation constant of the dichloro-complex has been determined spectrophotometrically to be $0.018 \mathrm{~kg}^{2} \mathrm{~mol}^{-2} .^{28}$ 
In contrast to ferrous chloride, there have been many attempts to determine equilibrium constants for the formation of ferric chloro-complexes in aqueous phase using spectrophotometry ${ }^{17,26,32,33,44-49}$ and potentiometry. ${ }^{50,51}$ Most of them, however, did not include the concept of ion activity, and thus there is a clear divergence in the values of formation constants for solutions of different ionic strength. Only a handful of publications present an estimate of equilibrium constants at zero ionic strength, either by extrapolation ${ }^{32,33,44,51}$ or by introducing activity coefficients for the ions. ${ }^{17,26,49}$ While the values for the formation constant of the monochloro-complex at room temperature are in good agreement, ranging from 19.1 to $33.1 \mathrm{~kg} \mathrm{~mol}^{-1},{ }^{17,44,49,51}$ there are large inconsistencies present for the formation constant of the dichloro-complexes ranging from 2 to $14 \mathrm{~kg} \mathrm{~mol}{ }^{-1} \cdot{ }^{17,26,33,44,49,51}$ The trichloro-complex formation constant is considerably smaller, ranging from 0.04 to $0.08 \mathrm{~kg} \mathrm{~mol}^{-1} \cdot{ }^{17,26,33,44}$ Note that cumulative formation constants have been converted to stepwise formation constants.

Despite these previous efforts, several questions remain unresolved. For instance, are the aforementioned methods sensitive only to the formation of first shell complexes, or could other associates also play a role? Do the water molecules incorporated in ferrous and ferric complexes exhibit a different dynamic behaviour compared to bulk water molecules? Is water beyond the first hydration shell affected by the ions and ion associates as well?

In the present study, we investigate the hydration behavior of iron(II) and iron(III) chloride salts in aqueous phase, using THz/FIR Fourier transform spectroscopy. THz/FIR absorption spectroscopy has proven to be a powerful tool to analyse electrolyte solutions at high concentrations. Using this technique, we have determined the low frequency absorption characteristics of several alkaline, ${ }^{7}$ alkaline earth, ${ }^{8}$ transition metal ${ }^{52}$ and lanthanum halides ${ }^{53}$ as well as hydrochloric and hydrobromic acid. ${ }^{54}$ The obtained frequency dependent absorption spectra exhibit distinguished ion specific bands, which are not present in the spectrum of bulk water. The spectra of these solutions can be well described by a linear superposition of (a) the absorption of bulk water and (b) the absorption of hydrated anions and cations. In case of manganese(II), nickel(II) and lanthanum(III) chloride and bromide, as well as hydrochloric and hydrobromic acid, we have shown that the nonlinear concentration dependence of absorption can be attributed to the formation of ion pairs. ${ }^{52-54}$ Thorough analysis of the experimental data allowed us to extract the single ionic features as well as the ion pair absorption spectra.

Here we investigate the concentration dependent THz/FIR absorption of iron(II) and iron(III) chloride in water with respect to the formation of ion associates. Using principal component analysis (PCA) as an unbiased mathematical procedure in conjunction with a chemical equilibrium model, we are able to dissect the experimental spectra into the absorption features of the various ions and complex species. This enables us to extract information about the vibrational properties of the solvated ions and ion associates, as well as their dynamical hydration shells. This study provides a proof of principle for the applicability of THz/FIR spectroscopy as an analytical tool for the simultaneous determination of $\mathrm{Fe}(\mathrm{II})$ and $\mathrm{Fe}$ (III) chloride at concentrations up to the solubility limit.

\section{Materials and methods}

\subsection{Materials}

The sample solutions were prepared by dissolving the weighed out amounts of $\mathrm{FeCl}_{2} \cdot 4 \mathrm{H}_{2} \mathrm{O}$ and $\mathrm{FeCl}_{3} \cdot 6 \mathrm{H}_{2} \mathrm{O}$ (Sigma Aldrich, $99 \%$ purity) in HPLC grade water. In order to prevent oxidation and hydroxide formation, all solutions were acidified with $\mathrm{HCl}$ to an $\mathrm{H}^{+}$concentration of $1 \mathrm{M}$, corresponding to $\mathrm{pH} 0$. For determination of water concentration in the samples, densities were measured at $20{ }^{\circ} \mathrm{C}$ using an Anton-Paar DMA58 density meter.

\subsection{FTIR measurements}

THz/FIR absorption measurements were carried out using a Bruker Vertex 80v FTIR spectrometer equipped with a liquid helium cooled silicon bolometer from Infrared Laboratories as detector (for more specific details about the experimental setup, see Schmidt et al. ${ }^{7}$ and supporting information therein). During the complete series of measurements, the sample compartment was constantly purged with technical grade dry nitrogen to avoid humidity effects of the air. The temperature of the sample cell was kept constant at $20 \pm 0.2{ }^{\circ} \mathrm{C}$ with a commercial high precision thermostat. For each single spectrum, 256 scans with a resolution of $2 \mathrm{~cm}^{-1}$ were averaged. The sample solutions were placed in a standard Bruker liquid cell between two parallel TPX windows of $4 \mathrm{~mm}$ thickness with a Kapton spacer of $c a .25 \mu \mathrm{m}$ thickness. The exact sample layer thickness was determined prior to each measurement using the Fabry-Pérot etalon effect of the empty cell.

Using Lambert-Beer's law, the frequency dependent absorption coefficient $\alpha(\tilde{v})$ of an aqueous solution is expressed as

$$
\alpha_{\text {solution }}(\tilde{\nu})=\frac{1}{d} \log \left(\frac{I_{\text {water }}(\tilde{\nu})}{I_{\text {solution }}(\tilde{\nu})}\right)+\alpha_{\text {water }}(\tilde{\nu})
$$

where $d$ is the sample thickness, $I_{\text {water }}(\tilde{v})$ and $I_{\text {solution }}(\tilde{v})$ are the transmitted intensities of the water reference and the sample, respectively, and $\alpha_{\text {water }}(\tilde{v})$ is a fit of the absorption spectrum of water. $^{52,55}$ In this way, artefacts due to reflections at the cell windows are minimized.

The contribution of $\mathrm{HCl}$ to the absorption was determined in an independent measurement and subtracted from all subsequent measurements, assuming a weak interaction with the coexisting ions.

For further data evaluation, we subtract the expected absorption of water in the sample to get the effective ionic absorption $\alpha_{\text {ion }}^{\text {eff }}$ :

$$
\alpha_{\text {ion }}^{\text {eff }}(\tilde{\nu})=\alpha_{\text {solution }}(\tilde{\nu})-\frac{c_{\mathrm{w}}}{c_{\mathrm{w}}^{0}} \alpha_{\text {water }}(\tilde{\nu})
$$

where $c_{\mathrm{w}}$ and $c_{\mathrm{w}}^{0}$ are the actual water concentrations in the solution and in pure water, respectively, as determined by density measurements. Deviations from linear concentration dependence can be examined by comparing the effective molar 
extinction $\varepsilon_{\text {ion }}^{\text {eff }}$ of each sample, which in turn is determined by dividing $\alpha_{\text {ion }}^{\text {eff }}$ by the actual salt concentration $c_{\mathrm{s}}$ :

$$
\varepsilon_{\text {ion }}^{\text {eff }}(\tilde{\nu})=\frac{\alpha_{\text {ion }}^{\text {eff }}(\tilde{\nu})}{c_{\mathrm{s}}}
$$

It is important to mention here that any changes in solvation water absorption induced by the ions are inherent in the effective ionic extinction $\varepsilon_{\text {ion }}^{\text {eff }}$. We assume that the interaction between each ion and surrounding water molecules can be understood by taking into account two contributions. ${ }^{7}$ Since the absorption properties of water are modified in the vicinity of ions, subtraction of the bulk water absorption from the sample absorption results in a negative contribution with the line shape of the water spectrum. The hydrated ion, however, has additional low frequency modes which can be described in terms of rattling modes and/or vibrational modes of the ionwater complexes. ${ }^{7,8}$

\section{Experimental results}

Sample solutions with concentrations ranging from $0.5 \mathrm{M}$ to $3.5 \mathrm{M}$ of $\mathrm{FeCl}_{2}$ and $\mathrm{FeCl}_{3}$, respectively, were measured using FTIR spectroscopy. The absorption spectra and the effective molar extinction spectra of both salts, respectively, are presented in Fig. 1 and 2. The positive value of the extinction over the entire
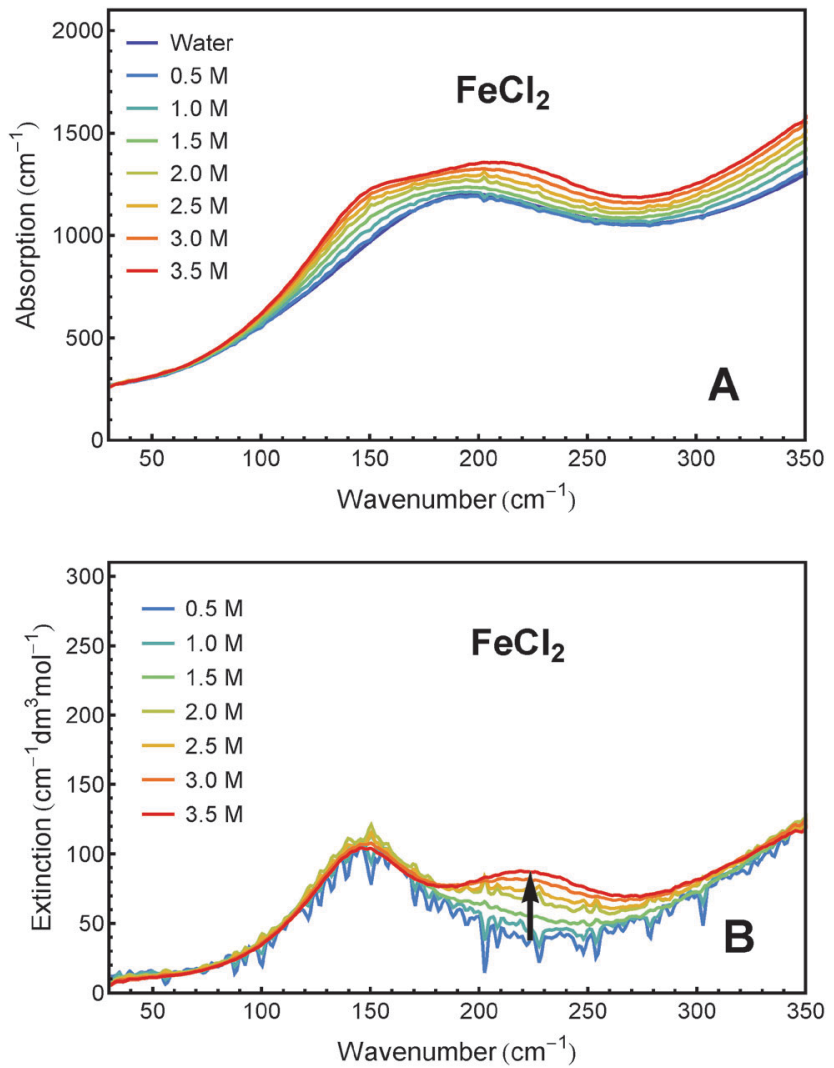

Fig. $1 \mathrm{THz} / \mathrm{FIR}$ absorption (A) and effective molar extinction spectra (B) of aqueous $\mathrm{FeCl}_{2}$ solutions at $20{ }^{\circ} \mathrm{C}$, as obtained from FTIR absorption measurements.
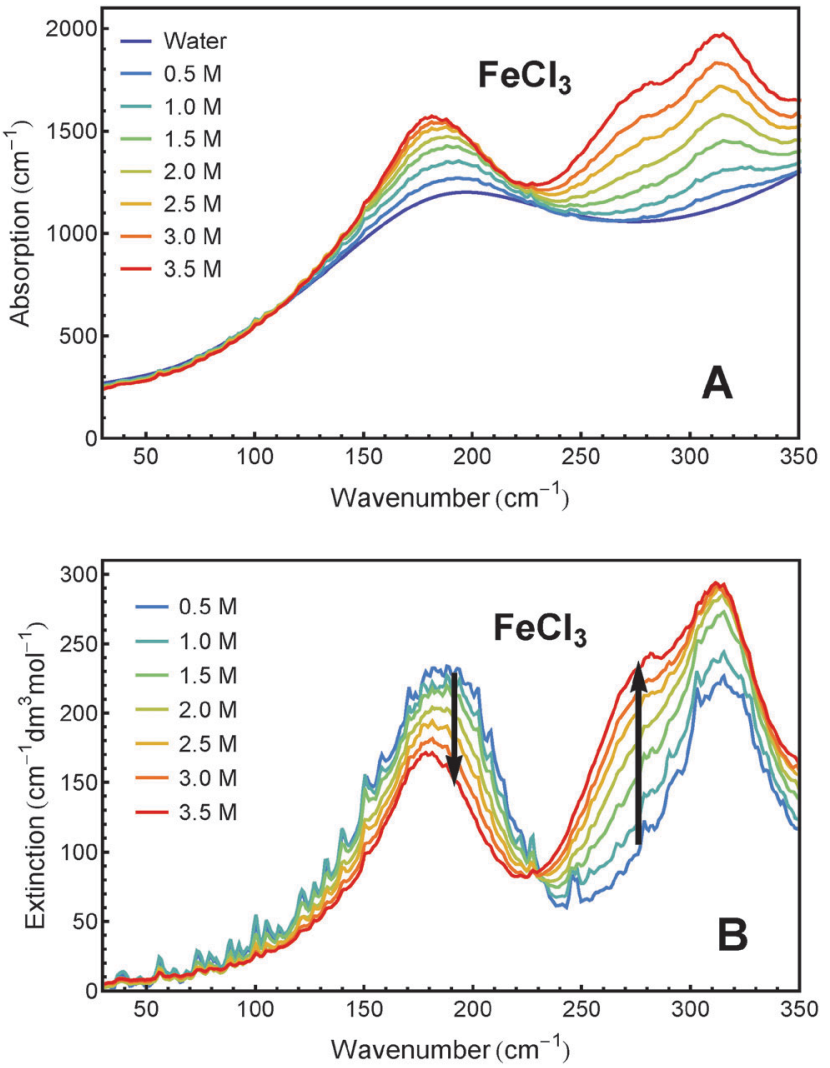

Fig. $2 \mathrm{THz} / \mathrm{FIR}$ absorption (A) and effective molar extinction spectra (B) of aqueous $\mathrm{FeCl}_{3}$ solutions at $20{ }^{\circ} \mathrm{C}$, as obtained from FTIR absorption measurements

frequency range can be attributed to the solvated ions. By examination of Fig. $1 \mathrm{~B}$ and $2 \mathrm{~B}$ it is obvious that the two iron chlorides have distinct nonlinear absorption features (marked with black arrows).

\section{Spectral dissection}

In order to deconvolute the experimental spectra into distinct components, we performed a principal component analysis (PCA) on the $\alpha_{\text {ion }}^{\text {eff }}$ spectra. Using this method (which has been described in detail before ${ }^{52}$ ), we were able to reduce both data sets of $\mathrm{FeCl}_{2}$ and $\mathrm{FeCl}_{3}$ to linear combinations of two components each, which include more than $96 \%$ of the information in both cases. The loading vectors and concentration dependent scores of the principal components of both salts are shown in Fig. 3 .

Although for both salts the results of the PCA are rather similar, the underlying mechanism seems to be different. Comparing different sets of association constants from literature ( $c f$. Section 2) it becomes evident that in the case of $\mathrm{FeCl}_{2}$, the solvated ions and the first ion associate $\mathrm{FeCl}^{+}$dominate over the whole concentration range, while in the case of $\mathrm{FeCl}_{3}$ the first and second associates, $\mathrm{FeCl}^{2+}$ and $\mathrm{FeCl}_{2}{ }^{+}$, dominate the solution's composition.

For the further evaluation of our data we make the assumption that next to $\mathrm{Fe}^{2+}, \mathrm{FeCl}^{+}, \mathrm{FeCl}^{2+}, \mathrm{FeCl}_{2}{ }^{+}$and $\mathrm{Cl}^{-}$the contribution of other species to the observed absorption is negligible. 

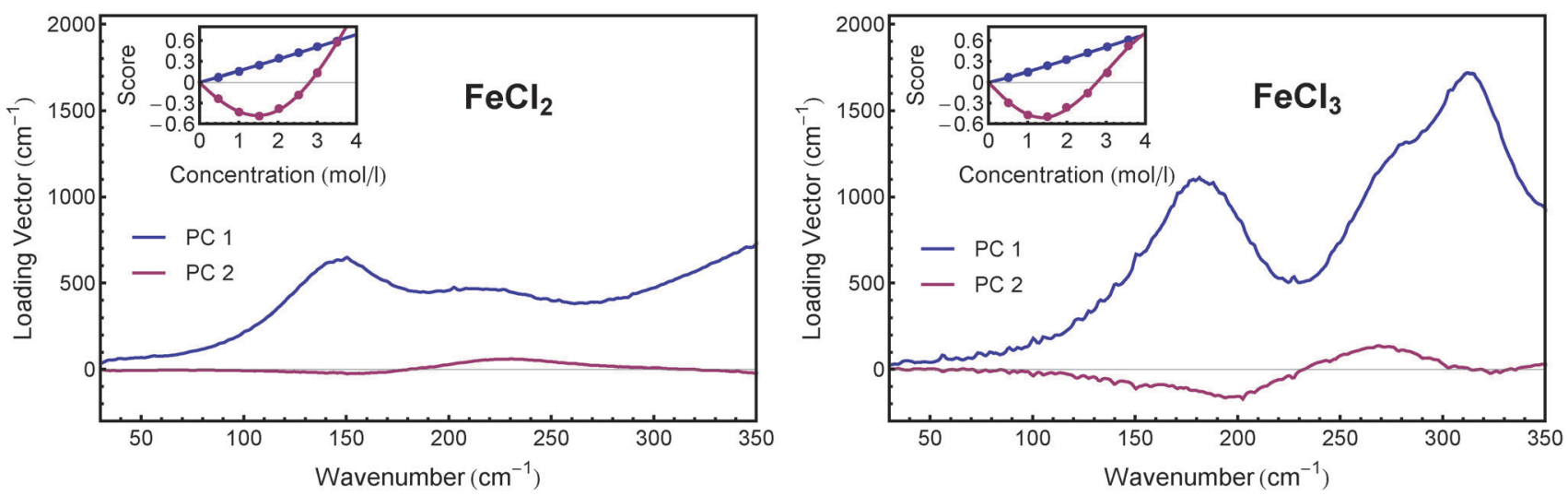

Fig. 3 First two principal components of $\mathrm{FeCl}_{2}$ (left) and $\mathrm{FeCl}_{3}$ (right). The insets show the associated scores as obtained from PCA.

Any changes in the concentration dependent absorption spectrum are attributed to a shift in the equilibrium:

$$
\begin{gathered}
\mathrm{Fe}^{2+}+\mathrm{Cl}^{-} \stackrel{K_{\mathrm{FeCl}}}{\rightleftharpoons} \mathrm{FeCl}^{+} \\
\mathrm{FeCl}^{2+}+\mathrm{Cl}^{-} \stackrel{K_{\mathrm{FeCl}_{3}}}{\rightleftharpoons} \mathrm{FeCl}_{2}^{+}
\end{gathered}
$$

The equilibrium constants $K_{\mathrm{FeCl}_{2}}$ and $K_{\mathrm{FeCl}_{3}}$ are defined by the ratio of product and educt concentrations $c_{\mathrm{x}}$ and their respective activity coefficients $\gamma_{x}$ according to the following equations:

$$
\begin{gathered}
K_{\mathrm{FeCl}_{2}}=\frac{c_{\mathrm{FeCl}^{+}}}{c_{\mathrm{Fe}^{2+}} \cdot c_{\mathrm{Cl}^{-}}} \cdot \frac{\gamma_{\mathrm{FeCl}^{+}}}{\gamma_{\mathrm{Fe}^{2+}} \cdot \gamma_{\mathrm{Cl}^{-}}} \\
K_{\mathrm{FeCl}_{3}}=\frac{c_{\mathrm{FeCl}_{2}+}}{c_{\mathrm{FeCl}^{2+}} \cdot c_{\mathrm{Cl}^{-}}} \cdot \frac{\gamma_{\mathrm{FeCl}_{2}+}}{\gamma_{\mathrm{FeCl}^{2+}} \cdot \gamma_{\mathrm{Cl}^{-}}}
\end{gathered}
$$

The activity coefficients of the mixed compounds $\mathrm{FeCl}^{+}, \mathrm{FeCl}^{2+}$ and $\mathrm{FeCl}_{2}^{+}$are not known. However, in first order approximation the activity coefficients of the iron containing species in both the numerator and denominator are similar $\left(\gamma_{\mathrm{FeCl}^{+}} \approx \gamma_{\mathrm{Fe}^{2+}}\right.$ and $\gamma_{\mathrm{FeCl}_{2}{ }^{+}} \approx \gamma_{\left.\mathrm{FeCl}^{2+}\right)}$. $^{32}$ This approximation is based on the assumption that for solutions of high ionic strength the activity coefficient is not determined by the charge of a species, but rather by the chemical structure. Experimental activity coefficients $^{56,57}$ were used to determine the Pitzer parameters for $\mathrm{FeCl}_{2}$ and $\mathrm{FeCl}_{3}$ according to the model of Harvie and Weare, ${ }^{58}$ which are shown in Table 1. These parameters allow us to predict the activity coefficient $\gamma_{\mathrm{Cl}^{-}}$in solutions of any ionic strength.

The respective underlying models for the effective ionic absorption are the following:

$$
\begin{aligned}
& \alpha_{\mathrm{ion}, \mathrm{FeCl}}^{\text {eff }}=c_{\text {single }} \cdot \varepsilon_{\text {single }}^{\text {eff }}+c_{\text {pair }} \cdot \varepsilon_{\text {pair }}^{\text {eff }} \\
& \alpha_{\text {ion, }, \mathrm{FeCl} l_{3}}^{\text {eff }}=c_{\text {pair }} \cdot \varepsilon_{\text {pair }}^{\text {eff }}+c_{\text {triple }} \cdot \varepsilon_{\text {triple }}^{\text {eff }}
\end{aligned}
$$

Table 1 Ion interaction parameters ${ }^{58} \beta^{(0)}, \beta^{(1)}$ and $C^{\phi}$ of $\mathrm{FeCl}_{2}$ and $\mathrm{FeCl}_{3}$

\begin{tabular}{lccc}
\hline Compound & $\beta^{(0)}$ & $\beta^{(1)}$ & \multicolumn{1}{l}{$C^{\phi}$} \\
\hline $\mathrm{FeCl}_{2}$ & $0.339 \pm 0.005$ & $1.48 \pm 0.06$ & $-0.019 \pm 0.001$ \\
$\mathrm{FeCl}_{3}$ & $0.42 \pm 0.01$ & $-0.028 \pm 0.002$ & $7.0 \pm 0.4$
\end{tabular}

Although we assume that the concentration of free $\mathrm{Fe}^{3+}$ is close to zero, the association constant for the formation of $\mathrm{FeCl}^{2+}$ cannot be neglected. Therefore we used the mean of four literature values in our calculation $\left(19.0,{ }^{49} 26.3,{ }^{17} 30,{ }^{44}\right.$ and $\left.33.1^{51}\right)$.

We performed a fit of the scores of the first two principal components with $K_{\mathrm{FeCl}_{2}}$ and $K_{\mathrm{FeCl}_{3}}$, respectively, as parameters, as has been described before. ${ }^{52}$ Clearly the fitted lines match the scores quite well (see insets in Fig. 3, solid lines). The resulting values for the equilibrium constants are presented in Table 2.

In addition to the equilibrium constants, we were also able to deduce the molar extinction spectra of the different solvated species. The result is displayed in Fig. 4 . Note that each of these spectra contains the anion contribution corresponding to the stoichiometry of the salt $\left(\varepsilon_{\mathrm{singl}, \mathrm{FeCl}_{2}}^{\text {eff }}=\varepsilon_{\mathrm{Fe}^{2+}}^{\text {eff }}+2 \varepsilon_{\mathrm{Cl}}^{\text {eff }}\right.$; $\varepsilon_{\text {pair }, \mathrm{FeCl}_{2}}^{\text {eff }}=\varepsilon_{\mathrm{FeCl}^{+}}^{\text {eff }}+\varepsilon_{\mathrm{Cl}^{-}}^{\text {eff }} ; \varepsilon_{\text {pair }, \mathrm{FeCl}}^{\text {eff }}=\varepsilon_{\mathrm{FeCl}^{+}}^{\text {eff }}+2 \varepsilon_{\mathrm{Cl}^{-}}^{\text {eff }} ; \varepsilon_{\text {triple, } \mathrm{FeCl}_{3}}^{\text {eff }}=$ $\left.\varepsilon_{\mathrm{FeCl}_{2}+}^{\text {eff }}+\varepsilon_{\mathrm{Cl}^{-}}^{\text {eff }}\right)$.

The extinction spectrum of $\mathrm{Fe}^{2+}+2 \mathrm{Cl}^{-}$in Fig. $4 \mathrm{~A}$ is dominated by one broad band at $150 \mathrm{~cm}^{-1}$ and the tail of a feature that peaks at $>350 \mathrm{~cm}^{-1}$. The spectrum of $\mathrm{FeCl}^{+}+\mathrm{Cl}^{-}$shows two resonances centered at $145 \mathrm{~cm}^{-1}$ and $230 \mathrm{~cm}^{-1}$, as well as a high frequency wing.

The extinction spectrum of $\mathrm{FeCl}^{2+}+2 \mathrm{Cl}^{-}$in Fig. 4B displays two strong peaks at $190 \mathrm{~cm}^{-1}$ and $315 \mathrm{~cm}^{-1}$. The spectrum of $\mathrm{FeCl}_{2}^{+}+\mathrm{Cl}^{-}$, however, shows a clear resonance around $170 \mathrm{~cm}^{-1}$ and at least two overlapping spectral features between $250 \mathrm{~cm}^{-1}$ and $350 \mathrm{~cm}^{-1}$.

\section{Global fit}

In our previous studies, we have performed a global fit of the aqueous ionic spectra of $\mathrm{MnCl}_{2}, \mathrm{NiCl}_{2}, \mathrm{MnBr}_{2}$ and $\mathrm{NiBr}_{2}$ and their differences, in order to pin down precise peak positions of

Table 2 Ion association constants obtained from score fitting

\begin{tabular}{lll}
\hline & $K\left(\mathrm{M}^{-1}\right)$ & $\log K$ \\
\hline $\mathrm{FeCl}_{2}$ & $0.13(1)$ & $-0.89(4)$ \\
$\mathrm{FeCl}_{3}$ & $0.49(8)$ & $-0.32(8)$
\end{tabular}



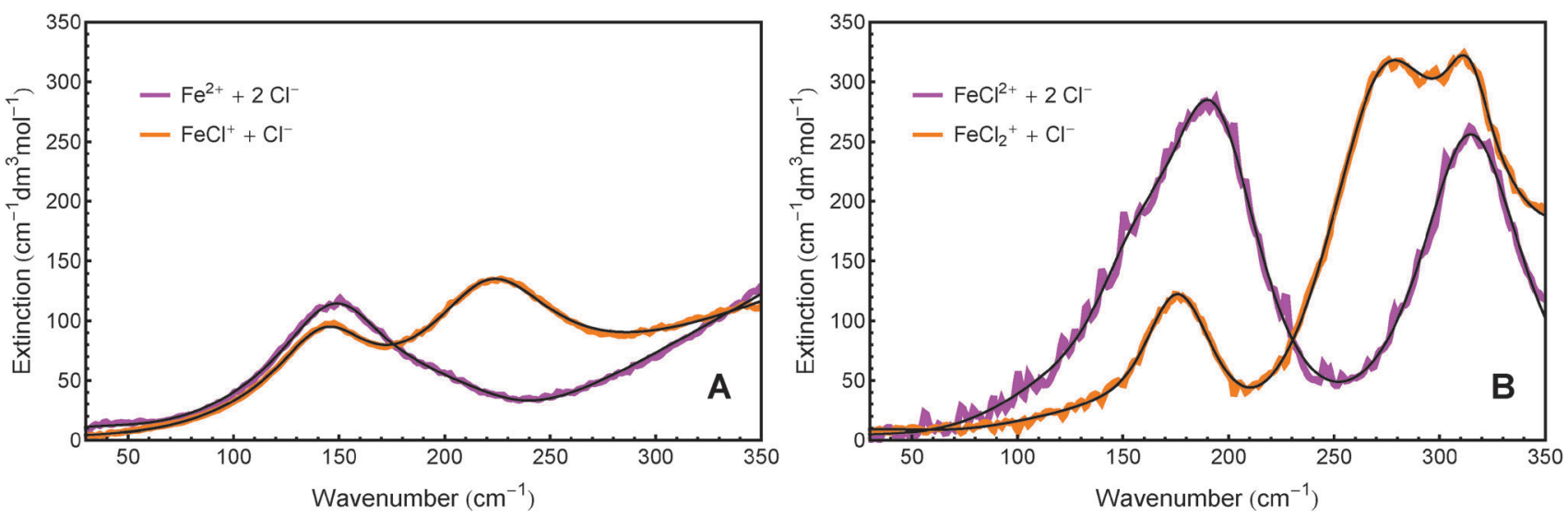

Fig. 4 Molar extinction spectra of the respective two main components in the $\mathrm{FeCl}_{2}(\mathrm{~A})$ and $\mathrm{FeCl}_{3}$ solutions (B), as obtained by fitting the score functions. The black lines represent the spectral fit described in Section 6 .

spectral features as well as to determine the effect of the ions on the water spectrum. ${ }^{22}$

In the global fit, the anion and cation bands are modeled by a modified damped harmonic oscillator function:

$$
\varepsilon_{\mathrm{DH}}(\tilde{\nu})=\frac{a_{0} w_{0}^{2} \tilde{\nu}^{2}}{4 \pi^{3}\left[\frac{w_{0}^{2} \tilde{\nu}^{2}}{\pi^{2}}+\left(\tilde{\nu}_{\mathrm{d}}^{2}+\frac{w_{0}^{2}}{4 \pi^{2}}-\tilde{\nu}^{2}\right)^{2}\right]}
$$

where $a_{0}$ is the amplitude, $w_{0}$ the width and $\tilde{v}_{\mathrm{d}}$ the center frequency of the mode. The corresponding center frequency of an unperturbed Brownian harmonic oscillator is given as $\tilde{\nu}_{0}=\sqrt{\tilde{\nu}_{\mathrm{d}}^{2}+\left(\frac{w_{0}}{2 \pi}\right)^{2}}$. The low and high frequency part of the spectra are modeled using the corresponding modes of the water spectrum ${ }^{52}$ scaled by factors $n_{\mathrm{LF}}$ and $n_{\mathrm{HF}}$. In addition to this, a negative contribution is present in each spectrum ( $c f$. Section 3.2), which can be modeled by the water extinction spectrum scaled by a factor $n_{\text {hydration }}$.

Here we extend the model to include the four spectra of $\mathrm{FeCl}_{2}$ and $\mathrm{FeCl}_{3}$. The inclusion of these in the global fit does not affect the previously determined parameters for the manganese and nickel bromide spectra significantly. Therefore the results of the bromide spectra are omitted here, and only the results for $\mathrm{MnCl}_{2}$ and $\mathrm{NiCl}_{2}$ are reported for comparison. The determined fit parameters are listed in Table 3.

We observe that several species have identical parameters, e.g. the linewidth of ionic bands, reducing the complexity of the fit. As an example for the various contributions to a fitting curve of one experimental spectrum, the spectrum of $\mathrm{Fe}^{2+}+2 \mathrm{Cl}^{-}$is displayed in Fig. 5.

While trying to fit the spectra of the ion associates, it is possible that overlapping bands of anionic and cationic species cause an ambiguity in the assignment. Sharma et al. previously have overcome this challenge by including the difference spectra of each metal chloride and bromide into the fit, thereby uncoupling the anion from cation contributions..$^{52}$ Since in the present work we lack the spectra of ferrous and ferric bromides for a direct comparison, we proceeded in an iterative approach: As a first step,
Table 3 Parameters used for the simultaneous fit of all spectra: perturbed and unperturbed center frequencies $\tilde{v}_{d}$ and $\tilde{v}_{0}\left(\mathrm{~cm}^{-1}\right)$, amplitude $a_{0}$ $\left(\mathrm{cm}^{-1} \mathrm{dm}^{3} \mathrm{~mol}^{-1}\right)$ and linewidth $w_{0}\left(\mathrm{~cm}^{-1}\right)$ of the water mode (WM), the modes of the cationic complexes (CM) and the anion modes (AM), minimum number of affected water molecules $n_{\text {hyd }}$ and scaling factors of the low and high frequency water modes $n_{\mathrm{LF}}$ and $n_{\mathrm{HF}}$. The $2 \sigma$ standard error is given in brackets in units of the last digit. Arrows indicate the restriction of a parameter to the same value for several bands. Arrows with an asterisk denote parameters, that have been fixed to the indicated value prior to fitting

\begin{tabular}{|c|c|c|c|c|c|c|}
\hline & $\begin{array}{l}\mathrm{Mn}^{2+}+ \\
2 \mathrm{Cl}^{-}\end{array}$ & $\begin{array}{l}\mathrm{Ni}^{2+}+ \\
2 \mathrm{Cl}^{-}\end{array}$ & $\begin{array}{l}\mathrm{Fe}^{2+}+ \\
2 \mathrm{Cl}^{-}\end{array}$ & $\begin{array}{l}\mathrm{FeCl}^{+}+ \\
\mathrm{Cl}^{-}\end{array}$ & $\begin{array}{l}\mathrm{FeCl}^{2+}+ \\
2 \mathrm{Cl}^{-}\end{array}$ & $\mathrm{FeCl}_{2}^{+}+$ \\
\hline$n_{\text {hyd }}$ & $14.5(5)$ & $\leftarrow$ & $\leftarrow$ & $7.3(6)$ & 21.4(7) & $16.9(5)$ \\
\hline$n_{\mathrm{LF}}$ & $17.0(5)$ & $\leftarrow$ & $\leftarrow$ & $8.4(7)$ & 23.2(7) & $20.3(4)$ \\
\hline$n_{\mathrm{HF}}$ & $20.0(5)$ & $\leftarrow$ & $20.8(4)$ & $12.5(6)$ & $25.0(7)$ & $18.7(4)$ \\
\hline \multicolumn{7}{|l|}{ WM } \\
\hline$\tilde{v}_{\mathrm{d}}$ & $117(2)$ & $\leftarrow$ & $\leftarrow$ & $\leftarrow$ & $\leftarrow$ & $\leftarrow$ \\
\hline$\tilde{v}_{0}$ & 136(9) & $\leftarrow$ & $\leftarrow$ & $\leftarrow$ & $\leftarrow$ & $\leftarrow$ \\
\hline$a_{0}$ & $382(32)$ & $\leftarrow$ & $\leftarrow$ & 297(45) & 1072(92) & $781(68)$ \\
\hline$w$ & $426(19)$ & $\leftarrow$ & $\leftarrow$ & $\leftarrow$ & $\leftarrow$ & $\leftarrow$ \\
\hline \multicolumn{7}{|l|}{ CM 1} \\
\hline$\tilde{v}_{\mathrm{d}}$ & 135(1) & 161(1) & 148(1) & 142(1) & 154(1) & $142(2)$ \\
\hline$\tilde{v}_{0}$ & $140(1)$ & $165(1)$ & 153(1) & 145(1) & 157(1) & $147(2)$ \\
\hline$a_{0}$ & 1561(29) & $1513(30)$ & $1926(38)$ & $1080(56)$ & 2181(48) & $597(45)$ \\
\hline$w_{0}$ & 231(1) & $\leftarrow$ & $\leftarrow$ & $195(7)$ & $205(1)$ & $\mathrm{Mn}^{2+} \leftarrow$ \\
\hline \multicolumn{7}{|l|}{ CM 2} \\
\hline$\tilde{v}_{\mathrm{d}}$ & 214(1) & $262(1)$ & $210(1)$ & 219(1) & 192(1) & 175(1) \\
\hline$\tilde{v}_{0}$ & $217(1)$ & 265(1) & 213(1) & 223(1) & 195(1) & $177(1)$ \\
\hline$a_{0}$ & $555(13)$ & $218(5)$ & $535(24)$ & $1544(55)$ & $4142(39)$ & $2269(52)$ \\
\hline$w_{0}$ & $\mathrm{CM} 1 \uparrow$ & $\leftarrow$ & $\leftarrow$ & $248(5)$ & $\mathrm{CM} 1 \uparrow$ & $158(3)$ \\
\hline \multicolumn{7}{|l|}{ CM 3} \\
\hline$\tilde{v}_{\mathrm{d}}$ & $358(3)$ & - & 0 & - & $313(1)$ & 271(1) \\
\hline$\tilde{v}_{0}$ & $360(3)$ & - & 37 & - & $315(1)$ & 273(1) \\
\hline$a_{0}$ & $322(24)$ & - & $46(4)$ & - & $3643(25)$ & $3582(14)$ \\
\hline$w_{0}$ & $\mathrm{CM} 1 \uparrow$ & - & $\mathrm{Mn}^{2+} \leftarrow$ & - & $\mathrm{CM} 1 \uparrow$ & $\mathrm{Mn}^{2+} \leftarrow$ \\
\hline \multicolumn{7}{|l|}{ CM 4} \\
\hline$\tilde{v}_{\mathrm{d}}$ & - & - & - & - & - & $313(1)$ \\
\hline$\tilde{v}_{0}$ & - & - & - & - & - & $315(1)$ \\
\hline$a_{0}$ & - & - & - & - & - & $1482(15)$ \\
\hline$w_{0}$ & - & - & - & - & - & $98(2)$ \\
\hline \multicolumn{7}{|l|}{$\mathrm{AM}$} \\
\hline$\tilde{v}_{\mathrm{d}}$ & 184(1) & $\leftarrow$ & $\leftarrow$ & $\leftarrow^{*}$ & $\leftarrow^{*}$ & $\leftarrow^{*}$ \\
\hline$\tilde{v}_{0}$ & 188(1) & $\leftarrow$ & $\leftarrow$ & $\leftarrow^{*}$ & $\leftarrow^{*}$ & $\leftarrow^{*}$ \\
\hline$a_{0}$ & $1343(12)$ & $1260(7)$ & $852(19)$ & $\frac{\leftarrow *}{2}$ & $\leftarrow^{*}$ & $\frac{\leftarrow *}{2}$ \\
\hline$w_{0}$ & CM $1 \uparrow$ & $\leftarrow$ & $\leftarrow$ & $\leftarrow^{*}$ & $\leftarrow^{*}$ & $\leftarrow^{*}$ \\
\hline
\end{tabular}



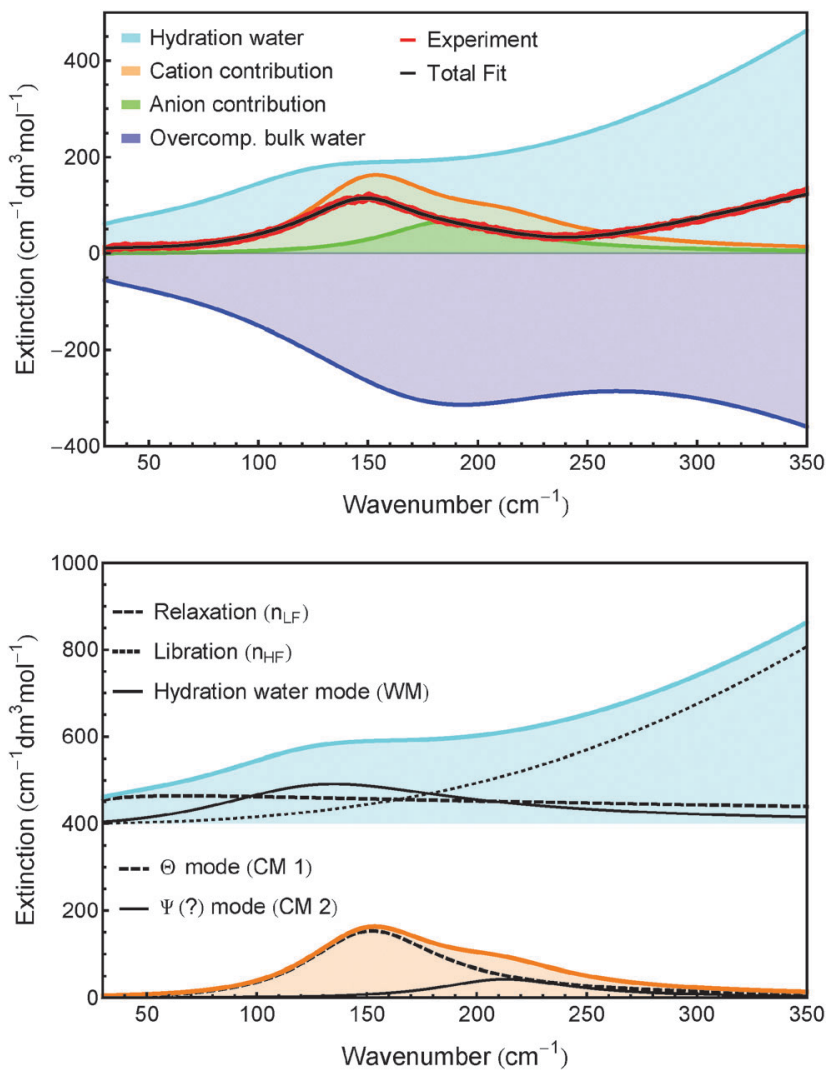

Fig. 5 Top: Shown are the distinct contributions to the fit of the spectrum of $\mathrm{Fe}^{2+}+2 \mathrm{Cl}^{-}$. Bottom: Hydration water spectrum (offset vertically for better display) and cation bands. $n_{\mathrm{LF}}, n_{\mathrm{HF}}, \mathrm{WM}, \mathrm{CM} 1$ and $\mathrm{CM} 2$ are defined in the caption of Table 3.

we included only the spectrum of $\mathrm{Fe}^{2+}+2 \mathrm{Cl}^{-}$into the fit of the manganese(II) and nickel(II) chloride and bromide spectra, thereby determining the $\mathrm{Cl}^{-}$mode. In a second step, this mode was then fixed in the spectra of $\mathrm{FeCl}^{+}+\mathrm{Cl}^{-}, \mathrm{FeCl}^{2+}+2 \mathrm{Cl}^{-}$and $\mathrm{FeCl}_{2}^{+}+\mathrm{Cl}^{-}$prior to inclusion of these spectra into the fit. After the global fit, the parameters of the chloride mode were fixed to the slightly changed new values. This was repeated iteratively until the change in the chloride fit parameters was smaller than the uncertainty. In Table 3, the fixed parameters are marked with an asterisk $\left({ }^{*}\right)$.

\section{Discussion}

\subsection{Association constants}

Prior to describing and comparing different values of ionassociation constants, it is essential to emphasize that the results are method dependent. One reason for this is the different degrees of experimental sensitivity towards other ion associates besides contact ion pairs. In fact when it comes to ion association, the real number of different species is much larger than the simple one-step reaction scheme suggests. As described by Marcus and Hefter, ${ }^{59}$ the ions undergo a series of reaction steps from (a) solvent separated ion pairs, in which both ions still have their full hydration sphere, over (b) solvent shared ion pairs, in which the hydration spheres are overlapping, to (c) contact ion pairs, in which one ion penetrates the hydration sphere of the other. The system becomes even more complex if a third ion is included. For example, an equilibrium constant found by the anion exchange method ${ }^{33}$ may be smaller than the one determined using potentiometry ${ }^{51}$ since the first is only sensitive towards contact ion pairs, while the latter is also sensitive to the presence of other ion pairs.

Here we performed a principal component analysis of our concentration dependent THz/FIR absorption spectra of $\mathrm{FeCl}_{2}$ and $\mathrm{FeCl}_{3}$ solutions, and fitted the scores with association constants $K_{\mathrm{FeCl}_{2}}$ and $K_{\mathrm{FeCl}_{3}}$, respectively, as fitting parameters. The logarithm of the determined parameters $K_{\mathrm{FeCl}_{2}}$ and $K_{\mathrm{FeCl}_{3}}$ is $-0.89(4)$ and $-0.32(8)$, respectively. These numbers are well below the values determined by other methods ranging from -0.37 to -0.12 in the case of $\mathrm{FeCl}_{2}{ }^{28,42,43}$ and 0.32 to 1.16 in the case of $\mathrm{FeCl}_{3} \cdot{ }^{17,26,33,44,49,51}$ This indicates that the THz/FIR absorption is especially sensitive to the formation of contact ion pairs, while the other methods might be more susceptible to solvent shared and solvent separated ion pairs.

\subsection{Band assignment}

6.2.1 The low frequency cation bands. The simultaneous fit of all spectra provides precise information about the spectral bands of the ions and ion-associates in aqueous phase. Each spectrum can be partitioned into a varying number of absorption bands, which we attribute to vibrations of the ion-water complexes. Out of these, one low frequency mode (denoted CM 1 in Table 3) is assigned to a cationic band centered between 130 and $170 \mathrm{~cm}^{-1}$. A similar band in the spectra of magnesium chloride and bromide at around $180 \mathrm{~cm}^{-1}$ has been attributed to a vibration of the hexaaqua complex of $\mathrm{Mg}^{2+}$, called $\Theta$ mode, in which the metal ion, together with two axial $\mathrm{H}_{2} \mathrm{O}$, moves against four equatorial $\mathrm{H}_{2} \mathrm{O}$ molecules. ${ }^{8}$ We propose that analogous vibrations of the octahedral water complexes of the metal ions $\mathrm{Mn}^{2+}, \mathrm{Ni}^{2+}$ and $\mathrm{Fe}^{2+}$, as well as the chlorosubstituted complexes of $\mathrm{Fe}^{2+}$ and $\mathrm{Fe}^{3+}$, are responsible for the bands between 130 and $170 \mathrm{~cm}^{-1}$. For the described vibrational geometry, the respective reduced masses of the hexaaqua complexes increase in the order $\mathrm{Mn}^{2+}<\mathrm{Fe}^{2+}<$ $\mathrm{Ni}^{2+}\left(40.21 \mathrm{~g} \mathrm{~mol}^{-1}, 40.39 \mathrm{~g} \mathrm{~mol}^{-1}, 40.93 \mathrm{~g} \mathrm{~mol}^{-1}\right)$, which in absence of other effects would result in a red-shift of the band. The metal-oxygen distance, however, decreases in the order $\mathrm{Mn}^{2+}>\mathrm{Fe}^{2+}>\mathrm{Ni}^{2+}(218 \mathrm{pm}, 213 \mathrm{pm}, 207 \mathrm{pm})^{1}$ due to increased ligand field stabilization. In absence of other effects, this strengthening of the $\mathrm{M}^{2+}-\mathrm{O}$ bond would lead to a blueshift. The blue-shift in the order $\mathrm{Mn}^{2+}<\mathrm{Fe}^{2+}<\mathrm{Ni}^{2+}$, that we in fact observe, is therefore the result of the counteracting effects due to mass reduction and bond strengthening. Using the relationship $k=(2 \pi \nu)^{2} \mu$ between effective force constant $k$, vibrational frequency $\nu$ and reduced mass $\mu$, we can calculate effective force constants of $44 \mathrm{~N} \mathrm{~m}^{-1}, 52 \mathrm{~N} \mathrm{~m}^{-1}$ and $65 \mathrm{~N} \mathrm{~m}^{-1}$ for the vibrational mode of the hexaaqua complexes of $\mathrm{Mn}^{2+}$, $\mathrm{Fe}^{2+}$ and $\mathrm{Ni}^{2+}$, respectively.

By exchanging a water ligand by chloride, the reduced mass for the $\Theta$ vibration of the octahedral $\mathrm{Fe}^{2+}$ complex is increased to $43.27 \mathrm{~g} \mathrm{~mol}^{-1}\left(\mathrm{Cl}^{-}\right.$axial) or to $45.08 \mathrm{~g} \mathrm{~mol}^{-1}\left(\mathrm{Cl}^{-}\right.$equatorial). 
In absence of other effects, this increase would cause a red-shift of the $\Theta$ mode by $c a$. $4-6 \%$ or $6-9 \mathrm{~cm}^{-1}$. In good agreement with this, we observe a red-shift of $6 \mathrm{~cm}^{-1}$ to $142 \mathrm{~cm}^{-1}$.

Moving from $\mathrm{Fe}^{2+}$ to $\mathrm{Fe}^{3+}$, the reduced mass of the monochloro complex remains the same, while the bond strength increases due to the higher charge of the metal center. Accordingly, the $\Theta$ mode is blue-shifted by $12 \mathrm{~cm}^{-1}$ to $154 \mathrm{~cm}^{-1}$. Exchanging another water molecule (in trans-position) by $\mathrm{Cl}^{-}$, the reduced mass for the $\Theta$ vibration is increased to $45.68 \mathrm{~g} \mathrm{~mol}^{-1}\left(\mathrm{Cl}^{-}\right.$axial) or to $48.98 \mathrm{~g} \mathrm{~mol}^{-1}\left(\mathrm{Cl}^{-}\right.$equatorial). In absence of any other effect, this increase is expected to lead to a red-shift of $3-4 \%$ or $5-6 \mathrm{~cm}^{-1}$. In fact, we observe a much larger red-shift of $12 \mathrm{~cm}^{-1}$. We attribute this to a weakening of the bond strength by the partial charge compensation of the metal center by the negatively charged ligands.

6.2.2 Other ionic bands. In all spectra we observe a second absorption feature around $170-270 \mathrm{~cm}^{-1}$ which is attributed to the cation. Possible assignments include: (a) The IR-active $\Psi$ mode described by Funkner et al. ${ }^{8}$ in which the central metal ion in an octahedral complex moves together with the four equatorial ligands against the two axial ligands; (b) a mode of the chloride ligand interacting with its hydration shell similar to the free anion; (c) a mode of hydration water (found at $157 \mathrm{~cm}^{-1}$ for bulk water). Two observations are noteworthy: first, the second mode of $\mathrm{Fe}^{2+}$ at $210 \mathrm{~cm}^{-1}$ is almost identical with regard to center frequency, amplitude and width to the mode of $\mathrm{Mn}^{2+}$ at $214 \mathrm{~cm}^{-1}$. And second, comparing $\mathrm{FeCl}_{2}^{+}$to $\mathrm{FeCl}^{2+}$, the second cation mode is red-shifted by $17 \mathrm{~cm}^{-1}$ or $10 \%$, which is very similar to the $8 \%$ red-shift of the first cation mode.

For $\mathrm{Fe}^{2+}$ we fitted a small amplitude mode at fixed center frequency of $0 \mathrm{~cm}^{-1}$, which we attribute to a relaxational process.

We observe only one band which can be attributed to the chloride anion in the spectra of $\mathrm{Mn}^{2+}+2 \mathrm{Cl}^{-}, \mathrm{Fe}^{2+}+2 \mathrm{Cl}^{-}$and $\mathrm{Ni}^{2+}+2 \mathrm{Cl}^{-}$at $184 \mathrm{~cm}^{-1}$, which is close to the chloride band around $190 \mathrm{~cm}^{-1}$ found for other salts. ${ }^{7,8}$ Due to the increased complexity of the spectra of $\mathrm{FeCl}^{+}+\mathrm{Cl}^{-}, \mathrm{FeCl}^{2+}+2 \mathrm{Cl}^{-}$and $\mathrm{FeCl}_{2}^{+}+\mathrm{Cl}^{-}$, we decided to fix the values of the anion band to the values deduced for $\mathrm{Fe}^{2+}+2 \mathrm{Cl}^{-}$prior to the fit.

6.2.3 The linewidths. Since the spectra of $\mathrm{Mn}^{2+}+2 \mathrm{Cl}^{-}$, $\mathrm{Fe}^{2+}+2 \mathrm{Cl}^{-}$and $\mathrm{Ni}^{2+}+2 \mathrm{Cl}^{-}$should lack any contributions of ion associates, we will call the bands in these spectra free ion bands. The linewidth for all free ion bands has been fitted as one parameter, which agrees well with the experimental spectra. The linewidth reflects the perturbation or damping of the vibrational modes of the ion-water complexes. Hence as a result we state that all free ions are subject to the same disturbance, which means that they are all connected to the same thermal bath. ${ }^{60}$

The linewidth of the modes attributed to the chloro-complexes of $\mathrm{Fe}^{2+}$ and $\mathrm{Fe}^{3+}$ varies. The first and third band of $\mathrm{FeCl}_{2}{ }^{+}$have the same width as the free ion bands $\left(231 \mathrm{~cm}^{-1}\right)$, while the width of the second band of $\mathrm{FeCl}^{+}$is slightly larger $\left(248 \mathrm{~cm}^{-1}\right)$. For all the other bands we observe a smaller width, ranging from $98 \mathrm{~cm}^{-1}$ to $205 \mathrm{~cm}^{-1}$. Distinct linewidths indicate that these modes are either connected to a different set of thermal bath states, or connected to the same bath, but with a different coupling parameter.
At this point, we can only speculate about the underlying molecular mechanism. We propose that the width of modes of solvated ions depends on the librational motions of the surrounding water molecules. These librations act as a random force causing line broadening. According to calculations by Vila Verde et al., water molecules between two ions (in case of a solvent-shared ion pair) or close to their point of contact (in case of a contact ion pair), are slowed down cooperatively. ${ }^{61}$ We therefore interpret the reduced linewidth as a consequence of inhibited librational motion of water close to the ion associates.

\subsection{Hydration water}

The low frequency mode at $117 \mathrm{~cm}^{-1}$ (called WM in Table 3) is attributed to a hydration water mode. It is most likely either due to a shifted hindered translational mode of the first shell hydration water, or due to an increased line strength of a second shell mode, which is not IR active in a bulk water environment. In addition to this, there are high and low frequency components attributed to the relaxational and librational modes of hydration water, scaled by factors $n_{\mathrm{LF}}$ and $n_{\mathrm{HF}}$. Finally, there is a negative contribution to the effective ionic extinction in the shape of the bulk water spectrum scaled by a factor $n_{\text {hyd }}$. Since the relaxational and librational parts are compensated by $n_{\mathrm{LF}}$ and $n_{\mathrm{HF}}$, the negative contribution is dominated by the shifted translational band of hydration water. The scaling factor $n_{\text {hyd }}$ provides an estimate of the minimum number of water molecules affected by the ions.

For the extinction spectra of $\mathrm{Mn}^{2+}, \mathrm{Fe}^{2+}$ and $\mathrm{Ni}^{2+}$ we can use the same fitting parameters for $n_{\text {hydration }}$ and $n_{\mathrm{LF}}$, while the effect on the librational mode of water $\left(n_{\mathrm{HF}}\right)$ is slightly higher for $\mathrm{Fe}^{2+}$ compared to $\mathrm{Mn}^{2+}$ and $\mathrm{Ni}^{2+} \cdot n_{\text {hydration }}$ is in the range of 14-15. In a previous study we found that $\mathrm{HCl}$ affects $c a .5$ water molecules and attributed this effect mainly to the anion. ${ }^{54}$ If we transfer this result to the present study, a minimum number of 4-5 water molecules are affected by the metal ions $\mathrm{Mn}^{2+}, \mathrm{Fe}^{2+}$ and $\mathrm{Ni}^{2+}$, which is in good agreement with a value of six water molecules of an octahedral geometry. ${ }^{62}$

For the ion-associate $\mathrm{FeCl}^{+}+\mathrm{Cl}^{-}$, the value obtained for the minimum number of affected water molecules is $n_{\text {hydration }}=7.3$, which is distinctly lower than for all other species. Assuming again a number of 5 water molecules affected by $\mathrm{Cl}^{-}$, the chloro-complex affects only a minimum number of 2-3 water molecules. This can only be explained if both the ferrous and chloride ions lose part of their influence on hydration water upon ion pairing.

For $\mathrm{FeCl}^{2+}+2 \mathrm{Cl}^{-}$we obtain a lower limit of $n_{\text {hydration }}=$ 21.4 affected water molecules, with similar values for the high and low frequency components $\left(n_{\mathrm{LF}}=23.2\right.$ and $\left.n_{\mathrm{HF}}=25.0\right)$. Subtracting the proposed effect of the anions, we deduce that 11-12 water molecules are affected by $\mathrm{FeCl}^{2+}$. This is surprisingly large, especially in comparison to $\mathrm{FeCl}^{+}$, in which the $\mathrm{Cl}^{-}$ ligand loses most of its effect on water upon ion pairing. We speculate that this indicates an effect beyond the first hydration shell of $\mathrm{Fe}^{3+}$.

The minimum number of affected water molecules $\left(n_{\text {hydration }}=16.9\right)$ as well as the low and high frequency 
components $\left(n_{\mathrm{LF}}=20.3\right.$ and $\left.n_{\mathrm{HF}}=18.7\right)$ are smaller in the case of $\mathrm{FeCl}_{2}^{+}+\mathrm{Cl}^{-}$compared to $\mathrm{FeCl}^{2+}+2 \mathrm{Cl}^{-}$. This can be explained by a compensation, or an effective shielding, of the positive charge of the central metal ion by the two axial chloride ligands.

\section{Quantitative analysis of $\mathrm{FeCl}_{2} / \mathrm{FeCl}_{3}$ mixtures}

As described in the previous sections, the absorption characteristics of $\mathrm{FeCl}_{2}$ and $\mathrm{FeCl}_{3}$ are distinctly different in the $\mathrm{THz}$ / FIR region. Their spectral signatures can therefore be used to distinguish ferrous and ferric iron species in aqueous solution.

Using Pitzer's equations ${ }^{58}$ and the complex formation constants $K_{\mathrm{FeCl}_{2}}$ and $K_{\mathrm{FeCl}_{3}}$, the distribution of different ions and ion complex species can be predicted for $\mathrm{FeCl}_{2}$ and $\mathrm{FeCl}_{3}$ solutions of any concentration and even for any mixture of both salts ( $c f$. Section 5). For a given water concentration, the extinction spectrum of water and the extinction spectra of the different complex species displayed in Fig. 4 can be used to predict the total absorption spectrum of any solution of $\mathrm{FeCl}_{2}$ and/or $\mathrm{FeCl}_{3}$ according to the following equation:

$$
\begin{aligned}
\alpha_{\text {tot }}= & c_{\text {water }} \varepsilon_{\text {water }}+c_{\mathrm{Fe}^{2+}}\left(\varepsilon_{\mathrm{Fe}^{2+}}+2 \varepsilon_{\mathrm{Cl}^{-}}\right)+c_{\mathrm{FeCl}^{+}}\left(\varepsilon_{\mathrm{FeCl}^{+}}+\varepsilon_{\mathrm{Cl}^{-}}\right) \\
& +c_{\mathrm{FeCl}^{2+}}\left(\varepsilon_{\mathrm{FeCl}^{2+}}+2 \varepsilon_{\mathrm{Cl}^{-}}\right)+c_{\mathrm{FeCl}_{2}}+\left(\varepsilon_{\mathrm{FeCl}_{2}}+\varepsilon_{\mathrm{Cl}^{-}}\right)
\end{aligned}
$$

The concentrations $c_{\mathrm{x}}$ can be calculated as functions of density $\rho$ and initial salt concentrations $c_{\mathrm{FeCl}_{2}}^{\text {init }}$ and $c_{\mathrm{FeCl}_{3}}^{\text {init }}$ of a given solution. It is therefore possible to determine the composition of an unknown mixed solution of $\mathrm{FeCl}_{2}$ and $\mathrm{FeCl}_{3}$ by fitting eqn (11) to the experimental absorption spectrum, using $c_{\mathrm{FeCl}_{2}}^{\text {init }}$ and $c_{\mathrm{FeCl}_{3}}^{\text {init }}$ as fitting parameters.

We have tested this method for a quantitative analysis of five sample solutions containing $\mathrm{FeCl}_{2}$ and $\mathrm{FeCl}_{3}$ in concentration ratios of $1 \mathrm{M} / 0 \mathrm{M}, 0.75 \mathrm{M} / 0.25 \mathrm{M}, 0.5 \mathrm{M} / 0.5 \mathrm{M}, 0.25 \mathrm{M} / 0.75 \mathrm{M}$ and $0 \mathrm{M} / 1 \mathrm{M}$. Each solution was acidified with $1 \mathrm{M} \mathrm{HCl}$ to prevent hydroxide formation and oxidation. The absorption spectra of these solutions after subtraction of the $\mathrm{HCl}$ contribution are presented in Fig. 6. The real concentrations

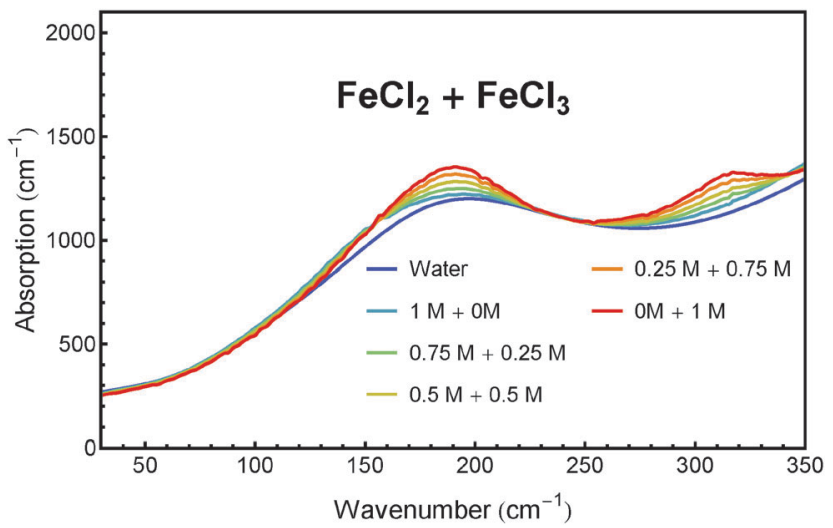

Fig. 6 Determined THz/FIR absorption of water and mixed solutions of $\mathrm{FeCl}_{2}$ and $\mathrm{FeCl}_{3}$ at $20{ }^{\circ} \mathrm{C}$.

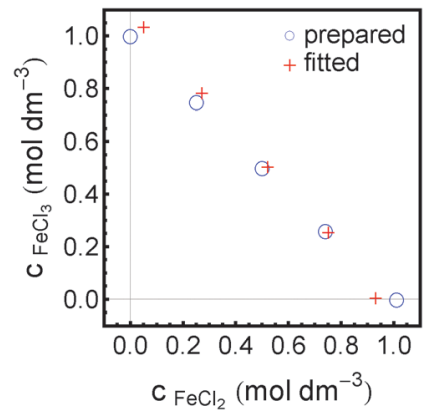

Fig. 7 Comparison of concentrations as prepared and as spectroscopically retrieved of $\mathrm{FeCl}_{2}$ and $\mathrm{FeCl}_{3}$ in five mixed sample solutions.

(known from sample preparation) and measured concentrations (obtained from fitting) of $\mathrm{FeCl}_{2}$ and $\mathrm{FeCl}_{3}$ are plotted in Fig. 7.

\section{Summary and conclusion}

We have measured the THz/FIR absorption spectra of acidified aqueous $\mathrm{FeCl}_{2}$ and $\mathrm{FeCl}_{3}$ solutions at concentrations of 0.5 to $3.5 \mathrm{M}$ in a frequency range of $30-350 \mathrm{~cm}^{-1}$. We observed a nonlinear concentration dependence of the effective ionic extinction for both salts. This can be rationalized in terms of the formation of chloro-complexes of $\mathrm{Fe}(\mathrm{II})$ and $\mathrm{Fe}(\mathrm{III})$, respectively. We were able to dissect the spectra of $\mathrm{FeCl}_{2}$ into the contributions of single ions and ion pair and the spectra of $\mathrm{FeCl}_{3}$ into the contributions of ion pair and ion triplet using principal component analysis. In addition, we were able to determine the ion association constants for both salts.

The logarithm of the formation constant of the ion pair $\mathrm{FeCl}^{+}$determined this way is $-0.89(4)$; the logarithm of the formation constant of the ion triplet $\mathrm{FeCl}_{2}{ }^{+}$is $-0.32(8)$. Both values are considerably lower than the values found in literature. ${ }^{17,26,28,33,42-44,49,51}$ However, we have to keep in mind that our measurements are susceptible mainly to the formation of contact ion pairs, while other methods might also be sensitive towards the formation of solvent separated or solvent shared ion pairs.

From the PCA of the $\mathrm{FeCl}_{2}$ spectra we extracted the molar extinction spectra of $\mathrm{Fe}^{2+}+2 \mathrm{Cl}^{-}$and $\mathrm{FeCl}^{+}+\mathrm{Cl}^{-}$; from the PCA of the $\mathrm{FeCl}_{3}$ spectra we extracted the molar extinction spectra of $\mathrm{FeCl}^{2+}+2 \mathrm{Cl}^{-}$and $\mathrm{FeCl}_{2}^{+}+\mathrm{Cl}^{-}$. We performed a global fit of all the extinction spectra and their differences, including the previous results for manganese(II) and nickel(II) chlorides and bromides. $^{52}$

For all cations we observe a peak centered around $150 \mathrm{~cm}^{-1}$, which we assign to the $\Theta$ vibration of the octahedral aqua- and chloro-complexes. This peak shifts for different cations, which can be explained by changes in reduced mass and bond strength of the complexes.

$\mathrm{Mn}^{2+}+2 \mathrm{Cl}^{-}, \mathrm{Ni}^{2+}+2 \mathrm{Cl}^{-}$and $\mathrm{Fe}^{2+}+2 \mathrm{Cl}^{-}$affect approximately the same amount of water, with a minimum number of affected water molecules of 14-15. The ion pair $\mathrm{FeCl}^{+}+\mathrm{Cl}^{-}$ affects only half as much water, which we attribute to the 
charge compensation of the paired ions. The ion pair $\mathrm{FeCl}^{2+}+$ $2 \mathrm{Cl}^{-}$, on the other hand, affects a much larger number of water molecules (ca. 21), which is an indication for a hydration effect extending beyond the first hydration shell of $\mathrm{Fe}^{3+}$. Again, the minimum number of affected water molecules is reduced upon association of another chloride ion to $\mathrm{ca} .17$ in the case of $\mathrm{FeCl}_{2}^{+}+\mathrm{Cl}^{-}$.

Furthermore, our analysis could be used successfully for a quantitative determination of concentrations of $\mathrm{FeCl}_{2}$ and $\mathrm{FeCl}_{3}$ in mixed solutions of total salt concentration of $1 \mathrm{M}$ with errors of less than $0.08 \mathrm{M}$. Thus we have provided a proof of principle that this technique can be used as an analytical tool for highly concentrated salt solutions.

\section{Acknowledgements}

This work is supported by the Cluster of Excellence RESOLV (EXC1069) funded by the Deutsche Forschungsgemeinschaft.

\section{References}

1 H. Ohtaki and T. Radnai, Chem. Rev., 1993, 93, 1157.

2 I. A. Heisler and S. R. Meech, Science, 2010, 327, 857.

3 H. J. Bakker, Chem. Rev., 2008, 108, 1456.

4 Y. Marcus, Chem. Rev., 2009, 109, 1346.

5 A. S. Merbach, L. Helm and E. Toth, The Chemistry of Contrast Agents in Medical Magnetic Resonance Imaging, John Wiley and Sons, Ltd, 2nd edn, 2013.

6 D. Laage and J. T. Hynes, Proc. Natl. Acad. Sci. U. S. A., 2007, 104, 11167.

7 D. A. Schmidt, Ö. Birer, S. Funkner, B. Born, R. Gnanasekaran, G. Schwaab, D. M. Leitner and M. Havenith, J. Am. Chem. Soc., 2009, 131, 18512-18517.

8 S. Funkner, G. Niehues, D. A. Schmidt, M. Heyden, G. Schwaab, K. M. Callahan, D. J. Tobias and M. Havenith, J. Am. Chem. Soc., 2012, 134, 1030.

9 K. J. Tielrooij, N. Garcia-Araez, M. Bonn and H. J. Bakker, Science, 2010, 328, 1006.

10 A. W. Omta, M. F. Kropman, S. Woutersen and H. J. Bakker, Science, 2003, 301, 347.

11 P. Giaquinta, M. Tosi and N. March, Phys. Chem. Liq., 1983, 13, 1.

12 I. Persson, Pure Appl. Chem., 2010, 82, 1901.

13 J. E. Enderby, Annu. Rev. Phys. Chem., 1983, 34, 155-185.

14 F. W. Outten and E. C. Theil, Antioxid. Redox Signaling, 2009, 11, 1029.

15 T. S. Koskenkorva-Frank, G. Weiss and W. H. Koppenol, Free Radical Biol. Med., 2013, 65, 1174.

16 A. C. Lasaga, J. Geophys. Res., 1984, 89, 4009.

17 A. Stefánsson, K. H. Lemke and T. M. Seward, 15th ICPWS Proceedings, 2008.

18 C. M. Johnson, J. L. Skulan, B. L. Beard, H. Sun, K. H. Nealson and P. S. Braterman, Earth Planet. Sci. Lett., 2002, 195, 141.

19 S. Schnell, S. Ratering and K.-H. Jansen, Environ. Sci. Technol., 1998, 32, 1530.
20 M. J. Verschoor and L. A. Molot, Limnol. Oceanogr.: Methods, 2013, 22, 113.

21 P. Praus and M. Blahutová, Fresenius' J. Anal. Chem., 2001, 369, 466.

22 C. O. Moses, A. T. Herlihy, J. S. Herman and A. L. Mills, Talanta, 1988, 35, 15.

23 S. O. Pehkonen, Y. Erel and M. R. Hoffmann, Environ. Sci. Technol., 1992, 26, 1731.

24 D. Y. Yegorov, A. V. Kozlov, O. A. Azizova and Y. A. Vladimirov, Free Radical Biol. Med., 1993, 15, 565.

25 A. A. Ensafi, M. A. Chamjangali and H. R. Mansour, Anal. Sci., 2004, 20, 645.

26 W. Liu, B. Etschmann, J. Brugger, L. Spiccia, G. Foran and B. McInnes, Chem. Geol., 2006, 231, 326.

27 J. Kozak, N. Jodlowska, M. Kozak and P. Koscielniak, Anal. Chim. Acta, 2011, 702, 213.

28 R. Zhao and P. Pan, Can. J. Chem., 2001, 79, 131.

29 L. V. Koplitz, D. S. McClure and D. A. Crerar, Inorg. Chem., 1987, 26, 308.

30 W. Liu, B. Etschmann, G. Foran, M. Shelley and J. Brugger, Am. Mineral., 2007, 92, 761.

31 G. S. Pokrovski, J. Schott, F. Farges and J.-L. Hazemann, Geochim. Cosmochim. Acta, 2003, 67, 3559.

32 G. A. Gamlen and D. O. Jordan, J. Chem. Soc., 1953, 1435.

33 Y. Marcus, J. Inorg. Nucl. Chem., 1960, 12, 287.

34 C. L. Standley and R. F. Kruh, J. Chem. Phys., 1961, 34, 1450.

35 M. D. Lind, J. Chem. Phys., 1967, 46, 2010.

36 M. Magini and T. Radnai, J. Chem. Phys., 1979, 71, 4255.

37 D. L. Wertz and M. D. Luter, Inorg. Chem., 1981, 20, 3118.

38 H. Kanno and J. Hirashi, J. Raman Spectrosc., 1982, 12, 224.

39 G. Giubileo, M. Magini, G. Licheri, G. Paschina, G. Piccaluga and G. Pinna, Inorg. Chem., 1983, 22, 1001.

40 K. Asakura, M. Nomura and H. Kuroda, Bull. Chem. Soc. Jpn., 1985, 58, 1543.

41 K. Murata, D. E. Irish and G. E. Toogood, Can. J. Chem., 1989, 67, 517.

42 C. A. Heinrich and T. M. Seward, Geochim. Cosmochim. Acta, 1990, 54, 2207.

43 D. A. Palmer and K. E. Hyde, Geochim. Cosmochim. Acta, 1993, 57, 1393.

44 E. Rabinowitch and W. H. Stockmayer, J. Am. Chem. Soc., 1942, 64, 335.

45 R. N. Heistand and A. Clearfield, J. Am. Chem. Soc., 1963, 85, 2566.

46 J. K. Rowley and N. Sutin, J. Phys. Chem., 1970, 74, 2043.

47 R. H. Byrne and D. R. Kester, J. Solution Chem., 1981, 10, 51.

48 G. R. Brubaker and R. A. Peterson, Inorg. Chim. Acta, 1989, $155,139$.

49 R. J. Millero, W. Yao and J. Aicher, Mar. Chem., 1995, 50, 21.

50 R. H. Byrne and D. R. Kester, Mar. Chem., 1976, 4, 275.

51 B. R. Tagirov, I. I. Diakonov, O. A. Devina and A. V. Zotov, Chem. Geol., 2000, 162, 193.

52 V. Sharma, F. Böhm, G. Schwaab and M. Havenith, Phys. Chem. Chem. Phys., 2014, 16, 25101. 
53 V. Sharma, F. Böhm, M. Seitz, G. Schwaab and M. Havenith, Phys. Chem. Chem. Phys., 2013, 15, 8383.

54 D. Decka, G. Schwaab and M. Havenith, Phys. Chem. Chem. Phys., 2015, 17, 8295.

55 J. E. Bertie and Z. Lan, Appl. Spectrosc., 1996, 50, 1047.

56 R. N. Goldberg, R. L. Nuttall and B. R. Staples, J. Phys. Chem. Ref. Data, 1979, 8, 923.

57 W. Kangro and A. Groeneveld, Z. Phys. Chem., 1962, 32, 110.
58 C. E. Harvie and J. h. Weare, Geochim. Cosmochim. Acta, 1980, 44, 981.

59 Y. Marcus and G. Hefter, Chem. Rev., 2006, 106, 4585.

60 A. Nitzan, Chemical Dynamics in Condensed Phases, Oxford University Press Inc., New York, 2006.

61 A. V. Verde and R. Lipowsky, J. Phys. Chem. B, 2013, 36, 10556.

62 H. Ohtaki, T. Yamaguchi and M. Maeda, Bull. Chem. Soc. Jpn., 1976, 49, 701. 